Revista Iberoamericana. Vol. LXVII, Núms. 194-195, Enero-Junio 2001, 91-103

\title{
GEOGRAFÍAS IMAGINARIAS: EL FACUNDO Y LA CAMPAÑA EN EL EJÉRCITO GRANDE DE DOMINGO FAUSTINO SARMIENTO
}

\author{
POR \\ Lelia Area \\ Universidad Nacional de Rosario
}

El arte y la política sólo tienen en común que están hechos de intrigas. Yo urdo mi literatura cada día. Para mí, un escritor comprometido es alguien que hace pasar la literatura por la política.

Jorge Luis Borges

Civilización y barbarie dice Domingo Faustino Sarmiento y esta fórmula dibuja el mapa imaginario ${ }^{1}$ de la historia argentina de la segunda mitad del siglo xIX, al mismo tiempo que se proyecta sobre el que se le asigna al siglo xx. Una fórmula que hace de soporte al relato de una biografía ejemplar: la del caudillo riojano Juan Facundo Quiroga, muerto diez años antes de que fórmula y biografía comenzaran a ser escritas. No obstante, ambas no son más que la excusa cifrada y narrativa, respectivamente, para permitir a Sarmiento instalar su proyecto de país. Un proyecto que intenta tanto distanciarse como distinguirse del aquí $y$ ahora políticos encarnados por esa figura mayor llamada Juan Manuel de Rosas. En este sentido, Sarmiento da los tonos (da el tono) sobre la forma en que Rosas debe ser percibido; una percepción mitológica y originaria dado que desde la "Introducción a la edición de 1845" lo expone como a ese "monstruo que nos propone el enigma de la organización política de la República” (24). ${ }^{2}$

\footnotetext{
1 Derek Gregory en su investigación sobre cartografías imaginarias plantea que los historiadores generalmente han presentado a la cartografía como la Medida de la Razón, un viaje narrativo y progresivo desde la oscuridad hasta la luz, en el curso del cual los mapas se han ido volviendo cada vez más “ajustados” y “objetivos”. Pero también es cierto —agrega— que actualmente existe una historiografía crítica que ha establecido la implicancia de los mapas en la constitución de los sistemas del poder del conocimiento. Esto nos compromete a llevar a cabo el intento de desarticular esas tecnologías de poder y ubicar a todo mapa en la perspectiva de cualquier tipo de práctica de representación. En este contexto y ubicados en el siglo xix vemos que será el Estado nacional quien le de al país, a las múltiples "naciones” que coyuntural y bélicamente convivían en esos territorios, un dibujo de sus fronteras. El Estado crea el mapa y el mapa crea la nación. Cuando las fronteras son delimitadas, los sentidos y, por tanto las identidades, serán finalmente normalizadas (Geographical Imaginations)

2 Las citas bibliográficas corresponden de aquí en adelante a Sarmiento, Domingo F. Facundo. Civilización y barbarie. A menos indicación expresa, los subrayados en el texto serán míos.
} 
Es precisamente a partir de la serie: fórmula, biografía, proyecto que el texto sarmientino adquiere su estatuto fundacional ya que se ha presentado a su generación (y a las posteriores) como un modo de leer lo político al mismo tiempo que se inscribe como un modo de escribir literario.

¿A qué llamamos textos de fundación? Desde nuestra perspectiva podemos arriesgar que son aquellos textos cuya trama discursiva imprime un modo de ver su época al mismo tiempo que se señala como el modo de leerla. A partir de un horizonte imaginario, delimita las fronteras (también imaginarias) de aquello que se puede decir mientras figura los silencios de lo que (proyectivamente) se propone leer mediante una insistencia temática y problemática atravesada por lo histórico.

En el caso de Sarmiento, este gesto de fundación es explícito dado que su objetivo tanto enunciado como anunciado desde la "Introducción a la edición de 1845" se ubica no sólo en la necesidad de "vencer al monstruo que propone el enigma" (241) sino la de ser el "que lo resuelva” (241). Aun si lo tomáramos desde su pura literalidad, la pretensión sarmientina se vuelve metafórica dado que implica abrir(se a) un espacio también fundante: el de aquél que encarnará la función de develar todas las significaciones del enigma con el solo objeto de dar a "la Tebas del Plata el rango elevado que le toca entre las naciones del Nuevo Mundo" (241). Es significativo observar de qué manera el desorden argumentativo que es el Facundo se organiza narrativamente a partir de esa grilla (de lectura) que es su "Introducción”. En ella, el escritor argentino se ve en la obligación de darnos ciertas pistas que funcionen con el carácter de pautas lectoras a seguir.

Micro-relato programático en sí mismo, la Introducción-grilla asume los tonos del texto a partir de su acápite, desde donde se exige del historiador que abandone todo rasgo de impasibilidad. ${ }^{3}$ Asumiendo la ímproba misión de descifrar el enigma que la Esfinge Argentina (Rosas) propone, aceptando la necesidad de "estudiar prolijamente las vueltas y revueltas de los hilos que lo forman y buscar en los antecedentes nacionales, en la fisonomía del suelo, en las costumbre y tradiciones populares, los puntos en que están pegados” (241), Sarmiento-cronista denuncia el estatuto de no-pasividad que modalizará su relato.

A través de dicho estatuto, el escritor acuña el emblema-Facundo a través del cual vislumbra la posibilidad de figurar "una manifestación de la vida argentina tal como lo han hecho la colonización y las peculiaridades del terreno, a lo cual creo necesario consagrar una seria atención, porque sin esto la vida y hechos de Facundo Quiroga son vulgaridades que no merecerían entrar sino episódicamente en el dominio de la historia” (247).

El movimiento en la construcción significante que Sarmiento lleva a cabo es claro: el emblema acuñado será ejemplar por lo que de singular tiene como personaje histórico. Sin embargo, este movimiento no se detiene ahí sino que le permite imprimir a dicho personaje una nueva torsión al proponer hacer de él y con él, un personaje literario. Su denuncia es explícita: "las preocupaciones clásicas europeas del escritor desfiguran al héroe (americano), a quien quitan el poncho para presentarlo desde el primer día con el frac, ni más ni menos como los litógrafos de Buenos Aires han pintado a Facundo con casaca de solapas,

${ }^{3}$ Privilegiada por Sarmiento del Cours de Littérature de Villemain, la cita subraya que "Je demande à l'historien l'amour justice impartiale en doit être impassible. Il faut, au contraire, qu'il souhaite, qu'il espère, qu'il souffre, ou soit heureux de ce qu'il raconte” (240). 
creyendo impropia su chaqueta, que nunca abandonó. Bien, han hecho un general, pero Facundo desaparece" (248)

Y, precisamente, para que Facundo no desaparezca Sarmiento le construye una estética política soportada por la ficcionalización del paisaje montado en "los detalles de la vida interior del pueblo argentino" (248) que servirán "para comprender su ideal, su personificación” (248). Una estética política concebida como "teatro [donde] va a representar la escena” (24) de una biografía moral (Facundo), estrategia de autor para acallar la otra bio-grafía (Rosas), aquélla que no debe escribirse aún: "El que haya leído las páginas que preceden - (pre)dice Sarmiento— creerá que es mi ánimo trazar un cuadro apasionado de los actos de barbarie que han deshonrado el nombre de don Juan Manuel de Rosas. Que se tranquilicen los que abriguen este temor. Aún no se ha formado la última página de esta biografía inmoral; aún no está llena la medida; los días de su héroe no han sido contados aún. Por otra parte, las pasiones que subleva entre sus enemigos son demasiado rencorosas aún para que pudieran ellos mismos poner fe en su imparcialidad o en su justicia. Es de otro personaje de quien debo ocuparme. Facundo Quiroga es el caudillo cuyos hechos quiero consignar en el papel. Diez años ha que la tierra pesa sobre sus cenizas, y muy cruel y emponzoñada debiera mostrarse la calumnia que fuera a cavar los sepulcros en busca de víctimas” (246).

El plan político de Sarmiento no consigue enmascarar sus ambiciones literarias, aquéllas a las que había consagrado muchas "vigilias, investigaciones prolijas y estudios meditados” (250), aquéllas por medio de las cuales se podía hacer "una justicia ejemplar y [adquirir] gloria como escritor argentino" (252) mientras se fustigaba "al mundo” (252) y se humillaba "la soberbia de los grandes de la tierra, llámense sabios o gobiernos" (252).

Sarmiento desea obtener trascendencia tanto en el espacio político como en el literario, pero es precisamente a través de éste último que la pretende lograr. ${ }^{4}$ En este sentido, la crítica ha coincidido en otorgarle el lugar de un escritor brillante aunque un tanto desarticulado. Si bien las imprecisiones no sólo son constatables al mismo tiempo que asumidas por el propio Sarmiento, el espacio de escritura que éste funda tiene como especial objetivo la

\footnotetext{
${ }^{4}$ Dice Ricardo Rojas: "Mientras Facundo alcanza en América vida militante, la Revue des Deux Mondes de París, publicó en 1846 una biografía elogiosa de Charles de Mazade, llegando el libro a servir para la propaganda en Europa contra Rosas y para aclarar la cuestión del Plata. Sarmiento, que hasta entonces fuera un periodista arrinconado en Chile, pasó a ser el autor de un libro famoso, su primer libro. Opúsculo improvisado y afortunado, sirvió por muchos años de galardón a Sarmiento y de arma contra Rosas, pero cuando Rosas cayó, y cuando aparecieron después Vicente Peñaloza y López Jordán, los últimos caudillos provinciales (1852-1872), esa obra siguió viviendo. Las ediciones del original fueron numerosas: dos en Chile (1845 y 1851), otra en New York (1868), corregidas las pruebas de imprenta por el hablista habanero Mantilla, la cuarta, de Hachette, en París (1874), sin contar la de El Progreso, anterior a todas ellas, y entre las siguientes la de Belín Sarmiento en Obras Completas (tomo VII, año 1896) y la de Rojas de 1916 Biblioteca Argentina (Nro. 12), con un prólogo que contiene la historia bibliográfica y la revaloración crítica de libro tan controvertido y duradero. Durante el siglo XIX, Facundo fue traducido, total o parcialmente: al francés por M. A. Giroud, oficial de la marina francesa; al alemán, por Eduardo Wappaus, profesor de Gotinga; al inglés por Mrs. Mann, esposa del educacionista norteamericano Horace Mann; al italiano, por el señor Fontana de Philippis, periodista que residió en Buenos Aires" (Para mayor información al respecto ver Rojas, El profeta de la pampa. Vida de Sarmiento, Cap. XV).
} 
exposición de lo que podríamos denominar una voluntad de estilo. Ella señala un lugar, que siempre involucró a sus materialidades performativas dado que comprometía en su enunciación al otro-lector. Un lector a quien se dirigen no sólo los temas del Facundo, sino que - y sobre todo — se le dedican los tonos con los que se mantiene el suspenso narrativo a través de apóstrofes, análisis que aparentan minuciosidad (y que enmascaran su ficcionalidad) repeticiones, apelaciones, es decir artificios de una retórica oral que se instala en los márgenes de una escritura política hasta convertirla en razón de su mezcla discursiva en un condensado estético. En relación precisamente con esto, Ricardo Piglia afirmará que:

Si Sarmiento se excede en su pasión un poco salvaje por la cultura es porque para él conocer es comparar. Todo adquiere sentido si es posible reconstruir las analogías entre lo que quiere explicar y otra cosa que está juzgada y escrita: la semejanza es la forma misteriosa, invisible, que hace visible el sentido. La cultura funciona sobre todo como repertorio de ejemplos que pueden ser usados como términos comparativos. (Piglia, “Notas” 17)

La expresividad ${ }^{5}$ sarmientina evalúa como ambiguos — cuando no, inútiles — los esquemas narrativos privilegiados por las novelas históricas europeas. Ni el amor funesto, ni la interpretación idílica de la naturaleza, ni la evasión tienen lugar en el montaje estético de su paisaje político

En este sentido, creo conveniente convocar la siempre actual lectura de Noé Jitrik en Muerte y resurrección de Facundo cuando evaluaba la operación sarmientina desde el marco de su "[e]spíritu fundamentalmente acumulativo y efectista [por medio del cual] Sarmiento trata menos de demostrar que de convencer", y avanzaba sobre el tema planteando lo "fácil [que era] determinar este objetivo: es como una suerte de presión que se ejerce sobre el lector, cubriéndolo de datos como para que se entere de algo cuya enormidad o monstruosidad tiene fatalmente que condenar./.../ Sarmiento se mueve simultáneamente en varios planos intencionales, necesita trasmitir nociones complejas para las cuales el lenguaje desnudo del dato o la interpretación no bastan. Y esta formulación

5 En su lúcido "Prólogo” a Campaña en el Ejército Grande Aliado de Sud América, Tulio Halperín Donghi analizaba que las "preferencias expresivas se corresponden así, en Sarmiento, con todo un modo de ver, de sentir, de pensar, a cuyo servicio viene a colocarse esa manera oratoria recogida a la vez de una remota, casi agónica tradición española y de otros ejemplos más recientes. La gravedad un poco solemne, acompañada a veces hasta bordear la monotonía, es adecuada a quien ve en cada objeto, en cada hecho ínfimo, un segmento siempre significativo de una muy vasta unidad de sentido, a quien confiere por lo tanto dignidad de historia a cuantas peripecias acontecen en torno suyo. La variedad regida y ordenada de un discurso ramificado y complejo, pero no quebrado, nos vuelve a su vez a una imagen de la realidad, sensible a toda su complejidad irreductible (que es captada gracias a unos modos de conocimiento en los cuales la sensibilidad y aun la pasión tienen su parte), pero capaz a la vez de integrar esa misma complejidad, es decir, de conocerla históricamente, como revelación y momento de un proceso cuya imagen unitaria sólo puede ser elaborada por la razón: he aquí como esa razón que se sumerge en el curso turbio y confuso de la historia sigue sin embargo dominándola. De esta manera la magnificencia de la prosa rica y compleja de Sarmiento da a su modo testimonio de su fe más honda, y el romanticismo del escritor Sarmiento no se resuelve en un problema de gusto o de influjos y tradiciones: nos remite a cada paso al romanticismo del pensador” (Halperín Donghi, Tulio, "Prólogo" Campaña XLII-XLIII). 
compleja sólo puede darse existiendo un espíritu literario, es decir un temperamento para el cual en la expresión se condensa la mayor cantidad pensable de valores que no pueden, además, sino presentarse juntos porque el desequilibrio los perjudicaría” (11).

Considero que Jitrik señala con verdadera inteligencia uno de los aspectos más importantes que hay que tener presentes cuando se trabaja con Sarmiento (lo que en nuestro caso significa trabajar sobre su Facundo): es literatura, entonces, lo que hace Sarmiento en el momento en que tiene que figurar la complejidad del espacio político. Es decir: Sarmiento ficcionaliza sus saberes, y de esta forma, su escritura adquiere el carácter de un acto estético en el que convergen diferentes instancias discursivas: una especie de poema, panfleto e historia como lo caracterizara, en alguna ocasión, el mismo escritor.

Sin embargo, este espacio de ficcionalización exige del lector que articule una constante operación de ajuste genérico con el objeto de poder atravesarlo. La contaminación de tramas genéricas es de tal magnitud que el lector siente que no tiene respiro para dirimir entre historia y ficción, tarea que finalmente abandona por imposible. Como inteligentemente lo propone Diana Sorensen Goodrich:

As one ponders the varied and complex forms of communication which Facundo has established with its reading public, it becomes necessary to observe the textual strategies it deplys in order to invite active reception. An interesting contradiction arises: while the reader's interest is kept alive, he or she is also confronted with considerable semantic instability. (41)

Esta sensación es una de las marcas más persistentes del texto ya que frente a la exigencia de tomar partido, nos enfrentamos a estrategias discursivas que nos exigen la adscripción al horizonte de la ficcionalidad como única prueba de verdad de la historia.

Sarmiento-narrador no se limita a la exposición de datos sino que apela a un proceso de ficcionalización ${ }^{6}$ mediante el cual monta una teatralidad cuya condición de posibilidad exige de un público in praesentia para que confirme el espectáculo de lo narrado. Sus contemporáneos ${ }^{7}$ acusan (y lo acusan de) dicha pretensión, dado que es evidente la dificultad que presenta el texto para establecer vínculos con la imagen de lo real.

\footnotetext{
${ }^{6}$ Recordemos que Hayden White, desde sus debates, proponía que la narrativa histórica no llega a desarticular las falsas creencias sobre el pasado, la vida humana, la naturaleza de una comunidad sino que, por el contrario, expone la forma en que la ficción — que siempre ha sido señalada como la modalidad específica de lo literario- presenta a partir de sus construcciones las pautas constitutivas de los acontecimientos "imaginarios”. Así, la narrativa histórica podría ser considerada como alegórica, es decir, como un discurso que dice una cosa y significa otra (Hayden White, "La cuestión de la narrativa" 41-74).

7 Alberdi, desde su beligerante oposición, y Alsina, a partir de sus paternales sugerencias, señalan: "Es el primer libro de historia que no tiene ni fecha ni data para los acontecimientos que refiere. Es verdad que esa misma omisión procura al autor una libertad de movimientos muy confortable, por lo cual avanza, retrocede, se detiene, va para un lado, vuelve al lado opuesto, todo con el método lógico con que un pescado rompe la onda del mar...” (Alberdi, La barbarie histórica de Sarmiento 11). No obstante, me interesa incluir aquí la acertada opinión de Diana Sorensen Goodrich en torno, precisamente, a esta cuestión: "Even if some critics have confidently granted the victory to Alberdi because of his calmer, more rational stance, it seems that such a proclamation entails a certain
} 
El diseño del paisaje y los tipos así lo demuestran. Sin embargo, no sólo a través del diseño textual podemos efectuar esta constatación, sino que ella se ve ratificada por el mismo Sarmiento quien admite haberlos dibujado a partir de recuerdos, reminiscencias, sin haber visitado los lugares de la escena o haber interrogado el suelo. Son precisamente estos gestos de la imaginación los que le permiten armar ese condensado ficcional y hacer de él - y con él - una estética de lo político. En este sentido, podríamos decir que en la escritura de Sarmiento se revela una cierta imagen del mundo, inseparable de la imagen que él se ha formado de lo que le toca hacer en el mundo.

Todo es posible en Sarmiento dado que sus horizontes argumentativos son construidos a partir de referencias puramente imaginarias. Es por todo esto que, como decíamos más arriba, su prueba de verdad será la ficcionalización del paisaje, paisaje narrativo que se vuelve paisaje político fundado por referencias literarias. Así, Sarmiento afirma sin rubores:

\begin{abstract}
Muchos filósofos han creído que las llanuras preparaban las vías al despotismo, del mismo modo que las montañas prestaban asidero a las resistencias de la libertad. Esta llanura sin límites que desde Salta a Buenos Aires y de Salta Mendoza, por una distancia de más de setecientas leguas, permite rodar enormes y pesadas carretas sin encontrar obstáculo alguno, por caminos en que la mano del hombre apenas ha necesitado cortar algunos árboles y matorrales, esta llanura constituye uno de los rasgos más notables de la fisonomía interior de la República [...] . Esta extensión de las llanuras imprime, por otra parte, a la vida del interior cierta tintura asiática que no deja de ser bien pronunciada. Muchas veces, al salir la luna tranquila y resplandeciente por entre las hierbas de la tierra, la he saludado maquinalmente con estas palabras de Volney, en su descripción de las ruinas. La pleine lune à l'Orient s'élevait sur un fond bleuâtre aux plaines rives de l'Euphrate. Y en efecto, hay algo en las soledades argentinas que trae a la memoria las soledades asiáticas; alguna analogía encuentra el espíritu entre la pampa y las llanuras que median entre el Tigris y el Eufrates; algún parentesco entre la tropa de carretas solitarias que cruzan nuestras soledades para llegar, al fin de una marcha de meses, a Buenos Aires y la caravana de camellos que se dirige hacia Bagdad o Esmirna. Nuestras carretas viajeras son una especie de escuadra de pequeños bajeles, cuya gente tiene costumbres, idiomas y vestidos peculiares que la distinguen de los otros habitantes, como el marino se distingue de los hombres de tierra. (13-14)
\end{abstract}

\footnotetext{
blindness to the critic's own act of analysis, to his sense of values and interpretative priorities. In fact, at the root of a polemic's discursive formation lies a certain contradiction: while it is underpinned by the dichotomy between truth and imposture, right and wrong (by which Western discourse has been obsessed), it stages the very impossibility of deciding between them)" (68). " / ../ le diré que en su libro, que tantas y tan admirables cosas tiene, me parece entrever un defecto general —el de la exageración, creo que tiene mucha poesía, si no en las ideas, al menos en los modos de locución. Ud. no se propone escribir un romance ni una epopeya, sino una verdadera historia social, política y hasta militar a veces, de un período interesantísimo de la época contemporánea. Siendo así, forzoso es no separarse en un ápice — en cuanto sea posible — de la exactitud y rigidez histórica..." (Ver "Notas" de Valentín Alsina al libro Civilización y barbarie, escritas en Montevideo en 1846. Estas notas fueron publicadas por primera vez por Estanislao Zeballos en Revista de Derecho, historia y letras, Tomo X y XI, 1901. Citado por Nora Dottori y Susana Zanetti 255).
} 
La escena sarmientina funda los modos de una ficción donde una impostación de totalidad simula escribir lo particular. Si tomamos la cita privilegiada más arriba desde un punto de vista al que podríamos denominar modelo para leer la geografía imaginaria que es el Facundo, ello nos permitirá comprobar lo que hasta ahora hemos estado exponiendo. Las geografías imaginarias de Sarmiento se inscriben desde analogías, las que a su vez llevan las marcas literarias. Así, reminiscencias de reminiscencias van armando un espacio consistente, precisamente, porque sus referencias se confirman sólo a partir de su enunciación ficcional: llanura/desierto, carretas/bajeles, pampa/Tigris-Eufrates, es decir, Sarmiento/ Volney construyen un condensado estético que hace de lo político una carta transgeográfica funcional.

Desde el registro de lo real es una descripción imposible pero desde el de lo imaginario, funda una geo-grafía posible, paradigma fuerte de una argumentación política, fundada en una figuración literaria. La literatura siempre será el modo de prueba del Facundo, su condición de posibilidad y de sobrevivencia; esa sobrevivencia a la que Sarmiento otorga un estatuto de legado nacional.

Un legado que encarna el destino de ser el diseño político de un proyecto de país expuesto como parte de una geografía imaginada, trazando desde fronteras quebradas, aún hoy, en múltiples nosotros y, por ende, dificultando el cierre de cuentas que sigue sin saldarse.

Ese MaPa QUe Dice Pampa

Tienen estos apuntes la gloria y la recomendación de haber pasado en resumen por la vista de D. Juan Manuel de Rosas, la víspera de la batalla, como si hubiese sido la mala suerte de aquel pobre hombre, que yo había de estarle zumbando al oído: ¡caerás... ya caes...ya has caído! Pues lo que leía en manuscrito estaba destinado para ver la luz después de su caída (Sarmiento, Campaña $62)^{8}$

En 1845, Sarmiento siente por intuición, es decir, imagina desde una estética que hace política la geografía de una Pampa a través de la cual realiza el montaje de una biografía programática llamada Facundo; recién en el año 1851 logrará “enfrentarse” en lo real a esa imaginación geográfica y es entonces cuando da cuenta del encuentro. Si bien coincidimos con Adolfo Prieto en evaluar este "encuentro” como un lugar común en la crítica y en los comentarios escolares del texto de Sarmiento, sobre todo en el hecho de destacar "admirativamente la circunstancia de que éste no tenía conocimiento directo de la franja central y oriental de la llanura pampeana en el momento de describirla”, me interesa privilegiar la anécdota(?) precisamente como “excusa teórica” a fin de poder ver a través de ella la devaluación imaginaria que sostiene la figuración geográfica en la Campaña. Una

\footnotetext{
${ }^{8}$ Las citas bibliográficas corresponden de aquí en adelante a Campaña en el Ejército Grande Aliado de Sud América de Domingo F. Sarmiento. A menos indicación expresa los subrayados en el texto serán míos.
} 
figuración sostenida por una pluma desacomodada, podríamos decir, dado que el escritor "asiste” —ahora él in praesentia - a varios desencantos a la vez. Tulio Halperín Donghi los califica como diversos modos de “desintegración” de ciertas certezas sarmientinas:

[El] acorde de forma y contenido, fruto de la coherencia alcanzada por el pensamiento de Sarmiento, caracteriza las grandes obras de la madurez: Facundo, Viajes, Recuerdos de provincia. Luego se produce algo que no sabríamos cómo llamar sino desintegración: desintegración en primer lugar de la fe que Sarmiento había puesto en las soluciones por él elaboradas para su país, que no resiste si daño a la confusa experiencia política que se abre en 1852 con la caída de Rosas. Desintegración también formal, vinculada no menos que con la anterior con esa reciente absorción de Sarmiento por una vida periodística extremadamente activa y agitada. Esa desintegración ha comenzado ya cuando Sarmiento se pone a escribir su Campaña en el Ejército Grande. (Campaña XLIII)

En este contexto, esa pluma desacomodada desdibuja aquella geografía, en la medida misma en que el proyecto político al cual ha adscrito también se le ha desdibujado. Sarmiento escribe su Campaña tras asumir que su participación en el proyecto de Urquiza está condenado al fracaso. El 23 de febrero de 1852, aquél le envía al caudillo entrerriano lo que podríamos denominar como el "acta de clausura” de su colaboración; desde una modalidad formal y hasta átona la carta remitida comunica la resolución del escritor sanjuanino de "regresar" a Chile. Aprovecha, entonces, la partida de un barco para Río de Janeiro "para tomar desde allí alguno de los muchos que salen para el Pacífico./ Aceleran esta resolución — dirá- el lenguaje y los propósitos de la proclama que ha circulado ayer, siendo mi intención decidida no suscribir a la insinuación amenazante de llevar un cintillo colorado, por repugnar a mis convicciones y desdecir a mis honorables antecedentes (Campaña 53).

En el marco de esta nueva opción de exilio, Sarmiento escribe la Campaña: ubicado, patéticamente, en el margen de un proyecto histórico en el que contaba no sólo participar, sino también encabezar, no resignado — sin embargo - a quedarse en ese margen, ${ }^{9}$ el cronista publica la primera parte del texto, denominada ad memorandum, en Río de Janeiro, en la que da a conocer una serie de documentos que avalaban su conducta y otros que dirigían el dedo acusador a la actuación de Urquiza. La segunda parte, publicada por el Nacional de Buenos Aires, se compone de un prólogo y una carta dirigida a Bartolomé Mitre; la tercera parte, escrita a fines de 1852, tras el fracaso de Urquiza se publica en Chile y contiene además una carta feroz dedicada al “querido Alberdi”, carta que dará paso a una encendida polémica entre dedicador y dedicado, el texto narrativo de la campaña propiamente dicha.

Es precisamente desde esta tercera parte que presenciamos el relato de aquella “desintegración” enunciada más arriba, donde un Sarmiento protagonista de la historia argentina troca sus otrora montajes geográficos en pedestres figuras ecuestres y se vuelve, en este marco, un jinete.

\footnotetext{
${ }^{9}$ Recordemos sus planes de contraofensiva en los que involucraba al general Mansilla, cuñado de Rosas, en el mismo momento en que ambos coinciden [sic] en el buque que materializaba su alejamiento, tras Caseros, de Buenos Aires.
} 


\begin{abstract}
¡A caballo, en la orilla del Paraná viendo desplegarse ante mis ojos en ondulaciones suaves pero infinitas hasta perderse en el horizonte, la Pampa, que había descrito en el Facundo, sentida por intuición, pues la veía por primera vez en mi vida! Paréme un rato a contemplarla, me hubiera quitado el quepí para hacerla el saludo de respeto, si no fuera necesario primero conquistarla, someterla a punta de espada, esta Pampa rebelde, que hace cuarenta años lanza jinetes a desmoronar, bajo el pie de sus caballos, las instituciones civilizadas de las ciudades. Echéme a correr sobre ella, como quien toma posesión y dominio. (Campaña 138)
\end{abstract}

A primera vista es un jinete seducido por la belleza de la llanura aunque su entrega a la contemplación es curiosamente breve; una contemplación que súbitamente se ve asaltada por el razonamiento y, finalmente, por el impulso de un conquistador. En un segundo momento, nos encontramos frente a la figura de un militar que se rinde ante el poderío del territorio encontrado viéndose obligado a sacar su espada y lanzarse a una apasionada (no obstante, controlada) conquista del objeto admirado: la pampa. En este contexto, es fácil observar cómo y de qué manera la atracción se va transformando en fascinación por la posesión de ese mismo territorio. Podríamos decir, entonces, que es un "encuentro" anhelado ansiosamente en la medida en que el tema de la pampa ha sido una de las insistencias más fuertes en varios de los escritos sarmientinos anteriores a la Campaña.

Si bien la geografía se le aparece, en un principio, con rasgos de mansedumbre, no tardará rápidamente en volvérsele hostil y peligrosa. Sin embargo, resulta un tanto paradójico constatar que es de aquélla primera imagen de mansedumbre de la que Sarmiento siente cuando saca la espada y clava las espuelas en el lomo del caballo. Acto simbólico si lo hay-a través del cual el personaje-Sarmiento avanza sobre un territorio cuya posesión es de otro; digamos aún más, una geografía definida como territorio que colabora con ese otro y allí encontramos la medida de su peligrosidad.

En este marco, el personaje - en su avance - toma precauciones precisas a fin de no correr el riesgo de transformarse de conquistador en conquistado: lleva las espuelas de Lavalle, aquéllas con las que el general se vistiese en la campaña de Quito y Rafael Lavalle:

Señor D. D. F. Sarmiento./ Montevideo, noviembre 20./ Mi querido compatriota y amigo: Tengo el gusto de dedicar $(\mathrm{s} / \mathrm{m}) a$ V. esas espuelas. Tienen para mí la recomendación de haber sido del uso de mi hermano el general Lavalle, y mandadas hacer por él en su campaña de Quito./ Su amigo,/ Rafael Lavalle. (Campaña 46)

Hermano del militar unitario, se las dedicará como regalo; porta también la espada que el ministro de Guerra de la República del Uruguay le remitiera a través del coronel Paunero tras haber sido informado que "el Sr. Sarmiento se hallaba sin espada/.../ Es de las de mejor calidad que he visto por aquí, y tiene la especialidad de deber su origen a la confianza que tenía Rosas de entrar triunfante en Montevideo” (Campaña 46).

Podríamos, así, afirmar que en su versión de la Campaña del Ejército Aliado, Sarmiento se instituye como el portador de los valores simbólicos de la libertad que se remontan a la guerra de la Independencia y cuyo primer paso fuera la liberación de Montevideo. La espada junto con las espuelas y estandartes del enemigo son —nos dice el sanjuanino- “los únicos recuerdos y los únicos trofeos adquiridos” (Campaña 63). 
Espadas, espuelas y equipaje fundan el escenario que Sarmiento-escritor arma para el Sarmiento-personaje político a fin de facilitarle la conquista del territorio pampeano mientras crea a su alrededor una protección miscelánea de objetos culturales-otros que operarán como resguardo de su "civilizado" cuerpo en el momento en que tiene que enfrentarse no sólo al "bárbaro” espíritu gauchesco sino a la socarrona desautorización de Urquiza:

El General me dijo: va a llover, y con tono de burla, y mojársele las plumas. Era el caso que yo era el único oficial del ejército argentino que en campaña ostentaba una severidad de equipo, estrictamente europeo. Silla, espuelas, espada bruñida, levita abotonada, guantes, quepí francés, palto en lugar de poncho, todo yo era una protesta contra el espíritu gauchesco. /.../ A la broma del General, pues, contesté con mi argumento favorito, dirigiéndome al arzón de la silla, desatando las correas que sujetaban la manta, sacando mi paltó y poniéndome por encima una capa blanca de goma elástica que había hecho traer de Buenos Aires. No había qué replicar. Despedíme así parapetado del General cuando ya caían esas gotas gruesas como el puño que anunciaban en la Pampa la proximidad de la tormenta./.../y para acabar con estos detalles de mi propaganda culta, elegante y europea, en aquellos ejércitos de apariencias salvajes, debo añadir que tenía botas de goma para el caso, tienda fuerte y bien construida, catre de hierro del peso de algunas libras, de manera de poder dormir dentro de una laguna, velas de esperma de noche y mesa, escritorio y provisiones de boca de cargarlo todo en un caballo. (Campaña 141-42)

Sarmiento se defiende, entonces, de esa nueva pampa, recientemente conocida, por medio de una parafernalia de "utilería” a la que todavía habría que agregarle: navaja de campo inglesa con eslabón, lanceta para caballos, un almacén de herramientas y una caramañola de platina. Asombrosa ostentación de objetos (la mayoría inútiles si se los piensa desde la perspectiva de su funcionalidad operativa en el territorio pampeano) portados por un oficial del ejército argentino que en campaña ostentaba una severidad de equipo estrictamente europeo.

No obstante, la utilidad reside en el hecho de que son objetos que se prestan, se ofrecen al uso del otro, ${ }^{10} \mathrm{y}$ al mismo tiempo adquieren un carácter ostentatorio, imprescindible para la propia Campaña-Sarmiento tan devaluada desde los parámetros valorativos del urquicismo. Una campaña que se tiene por ganada cuando el otro (re)conoce que esos objetos se vuelven pragmáticamente indispensables dado que en el mercado de una economía burguesa, es esencial que el propietario demuestre la necesidad de poseer (bienes devenidos objetos).

No obstante - y considerado desde otro punto de vista- estos objetos se vuelven emblemáticos dado que, al mismo tiempo, previenen que la barbarie contamine al propietario, es decir, lo salvaguardan de la infección de las costumbres de la campaña. Son objetos

$10 \mathrm{c} / . . /$ lo que al principio dio lugar a algunas pullas, a que contestaba victoriosamente por la superioridad práctica de mis medios. ¿¿ué está haciendo, Coronel? —Estoy componiendo el recado. —Yo no compongo mi silla nunca. —¿Quién tendrá fuego? decía un general en la marcha. —Yo, general, y sacaba una navaja de campo inglesa, con eslabón, lanceta para caballos y un almacén de herramientas. - Me muero de sed, decía alguno, mirando mi caramañola de platina, colgada en el arzón de la silla. A los seis días de campaña, la silla, la levita y el quepí estaban debidamente respetados” (Campaña 141). 
salvadores/constructores de una zona de seguridad para el que los posee. En este sentido, no sólo se vuelven una protección contra la barbarie ubicada en la pampa sino que - y sobre todo- - preservan de los “temores e incertidumbres fantásticas” que el horror vacui genera.

El temor latente que Sarmiento encarna en lo referente al desborde, le hace demarcar un círculo protector entre él mismo y la pampa enfrentada, aunque no dominada. El suyo es un equipaje monstruoso que lo protegerá, en la medida en que lo diferencia y, por ende, aleja imaginariamente, del tan temido y de-preciado ropaje de la barbarie: el poncho y el chiripá; vestuario que lo homogeneizaría con el otro: el gauchaje.

De todo esto se puede concluir, entonces, que el equipaje asegura la supremacía del dueño al mismo tiempo que es adoptado como un conjunto de elementos teatrales. Ellos darán relieve a la figura del escritor en la medida en que le otorgan los símbolos de pertenencia de una identidad "civilizada". En este contexto, la teoría del determinismo geográfico ${ }^{11}$ y las condiciones de vida hacen que Sarmiento se cuide de y en lo exterior y, en consecuencia al autorizarlo a afirmarse a través de la refracción de su apariencia.

A la lista de objetos se le agregan, por otra parte, dos mapas confeccionados en Londres, en uno, figura Buenos Aires, en el otro, sus alrededores. Es a través de ellos que Sarmiento controla el recorrido señalado por el baqueano que lo acompaña, un Calíbar devaluado en esta oportunidad que se equivocará al intentar exponer su saber de guía. Es que para Sarmiento, en 1851, la única lectura posible debe tornarse “civilizada” para así confirmar la validez no sólo del mapa sino — y sobre todo — la veracidad de su propietario como único poseedor del saber. No sólo esto: desde la perspectiva de un verdadero representante de "modernidad" Sarmiento valida el sentido cartográfico (King 18) del territorio con el objeto de garantizar su propia sobrevivencia. Sabe que solo el hecho de "figurar" en el mapa asegura la existencia no sólo en el "mundo" geográfica sino, especialmente, en el mundo real.

El nuevo baqueano del Ejército Grande no necesita instalar su lectura en los signos explícitos del territorio real sino que, por el contrario, traduce marcas mientras descifra las figuras que le vienen de un trozo de papel. Así, en el espacio que se (de)marca entre el que lee civilizadamente y el territorio a ver se ha incrustado un mapa, diseño imaginario de marcas y rastros figurados en la tierra.

El mapa, carta geográfica, le permite a ese nuevo baqueano apropiarse de una visión general en vez de tener que concentrarse tan sólo en lo particular y, en este sentido, la operación adoptada le garantiza un ahorro de tiempo, una acumulación y apropiación de saberes que le vienen de Londres. Asimismo, como reducción imaginaria de la extensión y materialización racional del puro cálculo y la medida, el mapa se vuelve indispensable para todo estratega y conquistador, además de ser el diseño imaginario de marcas y rastros

\footnotetext{
11 Dice Dardo Scavino al respecto: "Dos geografías se enfrentan en Sarmiento: las distancias secas —el desierto— y las vías húmedas — los ríos-; una Argentina de las extensiones inhóspitas, del pastoreo y la barbarie; otra fluvial, comercial y civilizada /.../ Sin embargo, si en Sarmiento hay una determinación: 'en última instancia’ de la geografía natural por sobre la geografía política, es que hay un uso estratégico del territorio que domina la lucha entre Civilización y Barbarie. Esta usa la llanura y sus colosales distancias como medio de defensa. Aquélla usa los ríos como instrumentos de ataque o invasión de la ‘morada sin límites' del caudillo” (66).
} 
inscriptos en un territorio al que conviene mucho más la idea de lentitud y la morosidad que la impronta de la extensión.

Al instalarse como la acumulación de las huellas descubiertas y las marcas dejadas por los antecesores, el mapa se presenta como el garante para lograr el ahorro del tiempo en la medida en que la economía de recursos y la impostación científica de la topografía vuelven a la "carta geográfica” una herramienta del burgués del siglo XIX al mismo tiempo al facilitarle la apropiación del saber inscripto en ella y habilitarlo para adquirir el conocimiento de lo inexplorado (Sarlo y Altamirano 37).

Ya en los libros de los viajeros ingleses, Sarmiento había leído acerca de la semejanza que para éstos poseía la comparación del mar con la pampa, por lo que no resulta casual que junto a los mapas lleve consigo "una aguja de marear, utilísima en aquél piélago sin límites de la Pampa” (Campaña 167). La posibilidad de la fusión aparecía ya en el Facundo cuando el paisaje se describía como "la imagen del mar en la tierra como en el mapa” (24) y dado que Sarmiento no había podido confrontar sus lecturas con lo real, se decide por la construcción imaginaria que proponen los primeros, a los que él otorga estatuto fundacional.

Así vemos cómo la lectura geográfica de Sarmiento se da a través de objetos de saber: los mapas, los viajeros ingleses y en un mismo gesto, invierte la direccionalidad lectora y con ella, la de su escritura - en función de la puesta en escena que genera. Una puesta en escena basada en la pretensión de querer ser reconocido a través de los objetos que posee y leído, a través de los textos que escribe. Sucede que, a través de los objetos, pretende ganarse el rango y el respeto en el espacio político del ejército y a través de sus escritos, el rango y el respeto del mundo “civilizado”. Rosas poseía títulos que señalaban su inscripción en lo político-real, Sarmiento construye los suyos en el espacio imaginario de lo políticoliterario: ambas categorías son múltiples. Tan es así que cierra el ad memorandum de la Campaña-Sarmiento, como la enunciáramos más arriba, con la adscripción a su agónico alter-ego, dialéctica polaridad de una escena política que llegaba a su fin:

Para mí no hay más que una época histórica que me conmueva, afecte e interese, y es la de Rosas. Éste será mi estudio único, en adelante, como fue combatirlo mi solo estimulante al trabajo, mi solo sostén en los días males. Si alguna vez hubiera querido suicidarme, esta sola consideración me hubiera detenido, como a las madres, que se conservan para sus hijos. Si yo le falto, ¿quién hará lo que yo hago por él? (Campaña 72)

Bibliografía

Alberdi, Juan Bautista. La barbarie histórica de Sarmiento. Buenos Aires: Ediciones Pampa y Cielo, 1964.

Dottori, Nora y Susana Zanetti. "Notas de Valentín Alsina al libro Civilización y barbarie”. Sarmiento, Domingo Faustino, Facundo. Buenos Aires: Biblioteca Ayacucho/ Hyspamérica, 1986.

Gregory, Derek. Geographical Imaginations. Cambridge, MA \& Oxford, UK: Blackwell, 1994.

Jitrik, Noé. Muerte y resurrección de Facundo. Buenos Aires: CEDAL, 1968.

King, Geoff. Mapping Reality. An Exploration of Cultural Cartographies. Nueva York: St. Martin’s Press, 1996. 
Piglia, Ricardo. “Notas sobre Facundo”. Revista Punto de Vista III/8 (1980): 14-20.

Prieto, Adolfo. Los viajeros ingleses y la emergencia de la literatura argentina. 18201850. Buenos Aires: Editorial Sudamericana, 1996.

Rojas, Ricardo. El profeta de la pampa. Vida de Sarmiento. Buenos Aires: Editorial Losada, 1945.

Sarlo, Beatriz y Carlos Altamirano. Ensayos argentinos. Buenos Aires: CEDAL, 1983. Sarmiento, Domingo F. Facundo. Civilización y barbarie. $8^{\mathrm{a}}$ edición. Buenos Aires: Editorial Espasa-Calpe, 1970.

Campaña en el Ejército Grande Aliado de Sud América. Edición, prólogo y notas de Tulio Halperín Donghi. México: Fondo de Cultura Económica, 1958.

Scavino, Dardo. Barcos sobre la pampa. Las formas de la guerra en Sarmiento. Buenos Aires: El Cielo por Asalto, 1993.

Sorensen Goodrich, Diana. Facundo and the Construction of Argentine Culture. Austin: University of Texas Press, 1996.

White, Hayden. "La cuestión de la narrativa en la teoría historiográfica actual”. El contenido de la forma. Narrativa, discurso y representación histórica. Barcelona: Ediciones Paidós, 1992. 41-74. 